\title{
Applying Dynamic Monte Carlo Simulation for Living Free Radical Polymerization Processes: Emphasis on Atom Transfer Radical Polymerization (ATRP)
}

\author{
Mamdouh A. Al-Harthi \\ Chemical Engineering Department, King Fahd University of Petroleum \& Minerals, \\ Dhahran 31261, \\ Saudi Arabia
}

\section{Introduction}

Modeling is the applications of methods to analyze complex, real-world problems in order to make predictions about what might happen with various actions. When it is too difficult, time consuming, costly or dangerous experiments, the modeler resort to computer simulations, or having a computer program imitate reality, in order to study situations and make decisions. Mathematical modeling is being used extensively in the field of polymer reaction engineering to ascertain various parameters. The use of mathematical modeling reduces the need for costly and time consuming experimentation. Mathematical models have been useful tools to enhance the understanding of polymerization processes and have been essential for process design, parameter estimation, sensitivity analysis, process simulation and optimization. Moreover, they are also useful for education and training purposes. [1-4] For example, several models have been proposed to simulate free-radical homopolymerization. The majority of these models predicting only averages molecular properties, but not complete distributions.

Various modeling techniques have been used in the field of polymer engineering depending on the suitability and on the targeted parameters. The most commonly used techniques are namely: 1) Instantaneous distributions, 2) Population balances with the method of moments, and 3) Monte Carlo method. The three methods have their own advantages and disadvantages. For examples, the method of moments cannot predict the molecular weight distribution (MWD) while the instantaneous distribution and Monte Carlo method can easily predict the MWD. In the case of copolymerizations, Monte Carlo technique is capable of predicting both average results and the full distribution. The focal point of this chapter would be on the Monte Carlo method since this technique can give full understanding about the polymerization processes. The modeler of the Mote Carlo simulation have full understanding of the molecular behavior in the reactor and use its programming skills to translate this understanding into valuable results.

Monte Carlo simulation is a probabilistic model involving an element of chance. Monte Carlo method provides approximate solutions to a variety of mathematical problems by 
performing statistical sampling experiments on a computer. Dynamic Monte Carlo (DMC) is a method for modeling the dynamic behaviors of molecules by comparing the rates of individual steps with random numbers. Unlike the Metropolis Monte Carlo method, which has been employed to study systems at equilibrium, the DMC method is used to investigate non-equilibrium systems such as a reaction, diffusion, and so-forth.

The synthesis and design of polymers with well-defined chain structures is a topic of high interest in academia and industry. Controlled radical polymerization (CRP) is fast becoming an important tool for producing polymers with customized microstructures.[1-2] The most well-established mechanisms of CRP are: (1) atom transfer radical polymerization $(\mathrm{ATRP}),{ }^{[3,4]}$ (2) nitroxide-mediated polymerization (NMP), ${ }^{[5,6]}$ and (3) reversible additionfragmentation chain transfer (RAFT).[7,8] Although the application of CRP processes is still limited to academia, they are promising techniques for the industrial production of specialty polymers. At this stage of CRP research, it is imperative to develop reliable mathematical models in order to better understand and improve CRP processes.

Since 1995, significant effort has been made towards the development, understanding, and application of ATRP to a wide range of monomers. In addition to its ability to control polymer micro-structural details, ATRP is very useful towards different reaction conditions. [9-11] ATRP can also copolymerize a variety of vinyl monomers to form random, gradient, block, and graft copolymers.[12-14] Among these previous chain architectures, gradient copolymers have received considerable interest because they form a new class of materials that have intermediate properties between random and block copolymers.[11]

Several research groups have developed mathematical models for ATRP. The method of moments has been used to study the effect of reactant concentration and rate constants on polymer properties, ${ }^{[15,16]}$ and also used to study the effect of diffusion-controlled reactions using the free volume theory.[17,18] Mathematical models using the concept of pseudo-kinetic rate constants and the method of moments have also been developed to describe ATRP.[19,20] Even though the method of moments can predict average molecular weights $\left(M_{n}, M_{w}\right.$, and $M_{z}$, for instance) and the polydispersity index (PDI), it cannot predict the complete molecular weight distribution (MWD) and it is well-known that the final properties of the polymer are not only a function of the average properties, but depend on distributions of molecular structural properties such as MWD, copolymer composition distribution (CCD), and sequence length distribution (SLD). The commercial software package PREDICI can be used to model polymerization processes and predict several polymer microstructural distributions, but it is only available to licensed users, while Monte Carlo simulation is an equally powerful technique that is relatively easy to implement, as demonstrated in this paper. PREDICI has been used to study the kinetics of ATRP, and to model chain end functionality.[21-24]

Several publications show the use of Monte Carlo models for different polymerization processes [25-30]. The focus of this chapter will be on ATRP in batch and semi batch reactors. Several case studies are presented to show the ability of DMC in predicting the full distributions.

\section{Model description}

We have followed Gillespie's algorithm for dynamic Monte Carlo simulation.[31] First, a control volume $(V)$ that contains the reactant molecules is defined at time zero. The reaction system is considered homogenous and several reactions can take place in the control 
volume. The experimental rates of these reactions are transformed into stochastic rates based on the number of molecules of each reactant present in the control volume at a given reaction time. In the case of copolymerization, the number of monomer molecules, $X_{A}$ and $X_{B}$, in the control volume at a given time is equal to their molar concentrations, $\left[M_{A}\right]$ and $\left[M_{B}\right]$, multiplied by Avogadro's number $(N)$ and the size of the control volume:

$$
\begin{aligned}
& X_{A}=\left[M_{A}\right] N V \\
& X_{B}=\left[M_{B}\right] N V
\end{aligned}
$$

Similarly, the number of initiator and catalyst molecules, $X_{i}$ and $X_{C}$, are calculated as follows:

$$
\begin{aligned}
X_{i} & =[I] N V \\
X_{C} & =[C] N V
\end{aligned}
$$

where $[I]$ and $[C]$ are the concentrations of initiator and catalyst, respectively.

The experimental rate constants are transformed into stochastic rate constants with the following equations:

$$
\begin{gathered}
k^{M C}=k^{\text {exp }} \text { for first order reactions } \\
k^{M C}=\frac{k^{\exp }}{V N} \text { for bimolecular reactions between different species } \\
k^{M C}=\frac{2 k^{\exp }}{V N} \text { for bimolecular reactions between similar species }
\end{gathered}
$$

This transformation involves the number of independent combinations of molecules participating in each reaction inside the control volume, as explained by Gillespie.[31]

The probability of any reaction $\left(P_{v}\right)$ taking place at a given time can be calculated with the equation

$$
P_{v}=\frac{R_{v}}{\sum_{v=1}^{N} R_{v}}
$$

where $R_{v}$ is the reaction rate of the $v^{\text {th }}$ reaction and $N$ is the total number of reactions in the polymerization mechanism. The following relation is used to determine which reaction type will take place at a given polymerization time

$$
\sum_{v=1}^{\mu-1} P_{v}<r_{1}<\sum_{v=1}^{\mu} P_{v}
$$

where $\mu$ is the number of the selected reaction type and $r_{1}$ is a random number uniformly distributed between $[0,1]$. Another random number is generated to determine the time interval $(\tau)$ between two consecutive reactions. The time step is related to the inverse of total stochastic rates and the natural logarithmic of $r_{2}$ according to the equation:[31] 


$$
\tau=\frac{1}{\sum_{v=1}^{N} R_{v}} \ln \left(\frac{1}{r_{2}}\right)
$$

The mechanism of ATRP proceeds in the same manner as conventional free radical polymerization: initiation, propagation, termination, and transfer reactions. In addition to this, it also includes an equilibrium reaction between active and dormant chains. This equilibrium reaction is in favor of the dormant chains and hence reduces the frequency of polymer radical termination or transfer reactions, thus imparting the living character of ATRP. Alkyl halides are frequently used as initiators in ATRP, and complexes between the metal halide and a ligand act as a catalyst. The mechanism for the copolymerization of comonomers $A$ and $B$ by ATRP is described in Equations (11) to (32).

Initiation

$$
\begin{gathered}
I+C \stackrel{k_{a}}{\longrightarrow} P R+C X \\
P R+C X \stackrel{k_{d}}{\longrightarrow} I+C \\
P R+M_{A} \stackrel{k_{i A A}}{\longrightarrow} R_{1, A} \\
P R+M_{B} \stackrel{k_{i B B}}{\longrightarrow} R_{1, B}
\end{gathered}
$$

Equilibrium and propagation

$$
\begin{gathered}
D_{r, A}+C \stackrel{k_{a, A}}{\longrightarrow} R_{r, A} \bullet+C X \\
D_{r, B}+C \stackrel{k_{a, B}}{\longrightarrow} R_{r, B} \bullet+C X \\
R_{r, A} \bullet+M_{A} \stackrel{k_{p, A A}}{\longrightarrow} R_{r+1, A} \bullet \\
R_{r, B} \bullet+M_{B} \stackrel{{ }_{p, B B}}{\longrightarrow} R_{r+1, B} \bullet \\
R_{r, A} \bullet+M_{B} \stackrel{{ }_{p, A B}}{\longrightarrow} R_{r+1, B} \bullet \\
R_{r, B} \bullet+M_{A} \stackrel{{ }_{p, B A}}{\longrightarrow} R_{r+1, A} \bullet \\
R_{r, A} \bullet+C X \stackrel{k_{d, A}}{\longrightarrow} D_{r, A}+C \\
R_{r, B} \bullet+C X \stackrel{k_{d, B}}{\longrightarrow} D_{r, B}+C
\end{gathered}
$$


Transfer to monomer

$$
\begin{aligned}
& R_{r, A} \bullet+M_{A} \stackrel{k_{t r}, A A}{\longrightarrow} P_{r}+R \bullet \\
& R_{r, A} \bullet+M_{B} \stackrel{k_{t r}, A B}{\longrightarrow} P_{r}+R \bullet \\
& R_{r, B} \bullet+M_{B} \stackrel{k_{t r, B B}}{\longrightarrow} P_{r}+R \bullet \\
& R_{r, B} \bullet+M_{A} \stackrel{k_{t r, B A}}{\longrightarrow} P_{r}+R \bullet
\end{aligned}
$$

Termination by combination

$$
\begin{aligned}
& R_{r, A} \bullet+R_{m, A} \bullet \stackrel{k_{t c, A A}}{\longrightarrow} P_{r+m} \\
& R_{r, A} \bullet+R_{m, B} \bullet \stackrel{k_{t c, A B}}{\longrightarrow} P_{r+m} \\
& R_{r, B} \bullet+R_{m, B} \bullet \stackrel{k_{t c, B B}}{\longrightarrow} P_{r+m}
\end{aligned}
$$

Termination by disproportionation

$$
\begin{aligned}
& R_{r, A} \bullet+R_{m, A} \bullet \stackrel{k_{t d, A A}}{\longrightarrow} P_{r}+P_{m} \\
& R_{r, A} \bullet+R_{m, B} \bullet \stackrel{k_{t d, A B}}{\longrightarrow} P_{r}+P_{m} \\
& R_{r, B} \bullet+R_{m, B} \bullet \stackrel{k_{t d, B B}}{\longrightarrow} P_{r}+P_{m}
\end{aligned}
$$

In Equations (11) to (32), $C$ and $C X$ are the catalyst in its low and high valence states, $M_{A}$ and $M_{B}$ are the comonomers, $R_{r, A} \bullet$ and $R_{r, B} \bullet$ are polymer radicals terminated in monomer $A$ and $B, P_{r}$ is a dead polymer chain, $D_{r}$ is a dormant polymer chain, $k_{i}$ is the initiation rate constant, $k_{a}$ is the activation rate constant, $k_{d}$ is the deactivation rate constant, $k_{p}$ is the propagation rate constant, $k_{t c}$ is the rate constant of termination by combination, $k_{t d}$ is the rate constant of termination by disproportionation, $k_{t r}$ is the transfer rate constant, and the subscripts $r$ and mindicate the number of monomer molecules in the chain. The subscript $A$ denotes that the chain ends with monomer $A$ and the subscript $B$ has an equivalent meaning.

\section{Polymerization rate constants}

The cross termination rate constants $\left(k_{t, A B}\right.$ and $\left.k_{t, B A}\right)$ were calculated using the following correlation:[32]

$$
\varphi_{t}=k_{t, A B} /\left[2\left(k_{t, A A} k_{t, B B}\right)^{1 / 2}\right]
$$


The cross propagation rate constants $\left(k_{p, A B}\right.$ and $\left.k_{p, B A}\right)$ were found from the reactivity ratios $r_{A}$ and $r_{B}$ and the values of $k_{p, A A}$ and $k_{p B B}$ :

$$
r_{A}=\frac{k_{p, A A}}{k_{p, A B}}, \quad r_{B}=\frac{k_{p, B B}}{k_{p, B A}}
$$

The reactivity ratios in free radical copolymerization are function of the type of the propagating species and the type of the monomer units and, generally, they do not depend on the reaction medium. Similar to the reaction rate constants, the reactivity ratios in ATRP are same as in conventional free radical copolymerization. Tables 1 and 2 list the numerical values of the kinetic rate constants and reactivity ratios used in our simulations. The rate constants were kept constant during the simulations, that is, we neglected diffusion effects.

\begin{tabular}{|c|c|c|}
\hline Parameter & Value & Reference \\
\hline$k_{\mathrm{pAA}}$ & $4.266 \times 10^{7} \exp (-7769 / R T)(\mathrm{L} / \mathrm{mol} \mathrm{s})$ & 33 \\
\hline$k_{p \mathrm{BB}}$ & $4.92 \times 10^{5} \exp (-4353 / R T)(\mathrm{L} / \mathrm{mol} \mathrm{s})$ & 34 \\
\hline$r_{A}$ & 0.52 & 35 \\
\hline$r_{\mathrm{B}}$ & 0.46 & 35 \\
\hline$k_{t c \mathrm{AA}}$ & 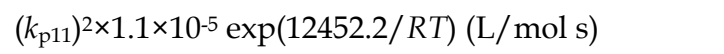 & 36 \\
\hline$k_{t d \mathrm{BB}}$ & $9.80 \times 10^{7} \exp (-701 / R T)(\mathrm{L} / \mathrm{mol} \mathrm{s})$ & 34 \\
\hline$k_{t d \mathrm{AA}}$ & 0 & 37 \\
\hline$k_{t c \mathrm{BB}}$ & 0 & 37 \\
\hline$k_{t r} \mathrm{~A}$ & $\left(k_{\mathrm{p} 11}\right) \times 2.198 \times 10^{-1} \exp (-2820 / T)(\mathrm{L} / \mathrm{mol} \mathrm{s})$ & 32 \\
\hline$k_{t r} \mathrm{~B}$ & $\left(k_{\mathrm{p} 22}\right) \times\left(\left(9.48 \times 10^{3} \times \exp (-13880 /(R T))\right) / 60\right)(\mathrm{L} / \mathrm{mol} \mathrm{s})$ & 32 \\
\hline$k_{a} \mathrm{~A}$ & $0.45(\mathrm{~L} / \mathrm{mol} \mathrm{s})$ & 43 \\
\hline$k_{d} \mathrm{~A}$ & $1.15 \times 10^{7}(\mathrm{~L} / \mathrm{mol} \mathrm{s})$ & 43 \\
\hline$k_{a} \mathrm{~B}$ & $0.055(\mathrm{~L} / \mathrm{mol} \mathrm{s})$ & 43 \\
\hline$k_{d} \mathrm{~B}$ & $8 \times 10^{7}(\mathrm{~L} / \mathrm{mol} \mathrm{s})$ & 43 \\
\hline $\begin{array}{l}\text { Initial Catalyst } \\
\text { Concentration } \\
\text { Initial Initiator } \\
\text { Concentration }\end{array}$ & $\begin{array}{l}0.087 \mathrm{~mol} / \mathrm{L} \\
0.087 \mathrm{~mol} / \mathrm{L}\end{array}$ & \\
\hline $\begin{array}{l}\text { Total Monomer } \\
\text { Concentration }\end{array}$ & $8.7 \mathrm{~mol} / \mathrm{L}$ & \\
\hline$M W_{\mathrm{A}}$ & $104.14(\mathrm{~g} / \mathrm{mol})$ & \\
\hline$M W_{\mathrm{B}}$ & $100.13(\mathrm{~g} / \mathrm{mol})$ & \\
\hline
\end{tabular}

Table 1. Kinetic rate constants and physical properties for styrene (1) -methyl methacrylate (2) copolymerization. 


\begin{tabular}{|c|c|c|}
\hline Parameter & Value & Reference \\
\hline$k_{p \mathrm{AA}}$ & $1.05 \times 10^{8} \exp (-3663 / R T)(\mathrm{L} / \mathrm{mol} \mathrm{s})$ & 38 \\
\hline$k_{p \mathrm{BB}}$ & $4.92 \times 10^{5} \exp (-4353 / R T)(\mathrm{L} / \mathrm{mol} \mathrm{s})$ & 33 \\
\hline$r_{A}$ & 0.14 & 40 \\
\hline$r_{B}$ & 1.3 & 40 \\
\hline$k_{t c \mathrm{AA}}$ & $3.30 \times 10^{12} \exp (-5400 / R T)(\mathrm{L} / \mathrm{mol} \mathrm{s})$ & 41 \\
\hline$k_{t d \mathrm{BB}}$ & $9.80 \times 10^{7} \exp (-701 / R T)(\mathrm{L} / \mathrm{mol} \mathrm{s})$ & 34 \\
\hline$k_{t d \mathrm{AA}}$ & 0 & 37 \\
\hline$k_{t c \mathrm{BB}}$ & 0 & 37 \\
\hline$k_{t r} \mathrm{~A}$ & $4.62 \times 10^{4} \times \exp (-5837 / R T)(\mathrm{L} / \mathrm{mol} \mathrm{s})$ & 32 \\
\hline$k_{t r} \mathrm{~B}$ & $\left(k_{p 22}\right) \times\left(9.48 \times 10^{3} \times \exp (-13880 /(R T) / 60)(\mathrm{L} / \mathrm{mol} \mathrm{s})\right.$ & 32 \\
\hline$k_{a} \mathrm{~A}$ & $0.1(\mathrm{~L} / \mathrm{mol} \mathrm{s})$ & 43 \\
\hline$k_{d} \mathrm{~A}$ & $1 \times 10^{8}(\mathrm{~L} / \mathrm{mol} \mathrm{s})$ & 43 \\
\hline$k_{a} \mathrm{~B}$ & $0.5(\mathrm{~L} / \mathrm{mol} \mathrm{s})$ & 43 \\
\hline$k_{d} \mathrm{~B}$ & $1 \times 10^{7}(\mathrm{~L} / \mathrm{mol} \mathrm{s})$ & 43 \\
\hline $\begin{array}{l}\text { Initial Catalyst } \\
\text { Concentration }\end{array}$ & $0.087 \mathrm{~mol} / \mathrm{L}$ & \\
\hline $\begin{array}{l}\text { Initial Initiator } \\
\text { Concentration }\end{array}$ & $0.087 \mathrm{~mol} / \mathrm{L}$ & \\
\hline $\begin{array}{l}\text { Total Monomer } \\
\text { Concentration }\end{array}$ & $8.7 \mathrm{~mol} / \mathrm{L}$ & \\
\hline$M W_{\mathrm{A}}$ & $53.15(\mathrm{~g} / \mathrm{mol})$ & \\
\hline$M W_{\mathrm{B}}$ & $100.13(\mathrm{~g} / \mathrm{mol})$ & \\
\hline
\end{tabular}

Table 2. Kinetic rate constants and physical properties for the acrylonitrile (1) - methyl methacrylate (2) copolymerization.

\section{Results and discussions}

The DMC model was applied to describe the copolymerization of styrene/methyl methacrylate, and of acrylonitrile/methyl methacrylate. These comonomer combinations were chosen because they have significantly different reactivity ratios, which will lead to the production of copolymers with distinct CCDs and SLDs. Reaction rate constants were kept constant during the simulations, that is, we neglected diffusion effects.

During living polymerization, the polymer average chain length increases linearly with monomer conversion, the polydispersity index approaches unity and, as a result, the molecular weight distribution is narrow, as shown in Figures 2.a to 2.c. 

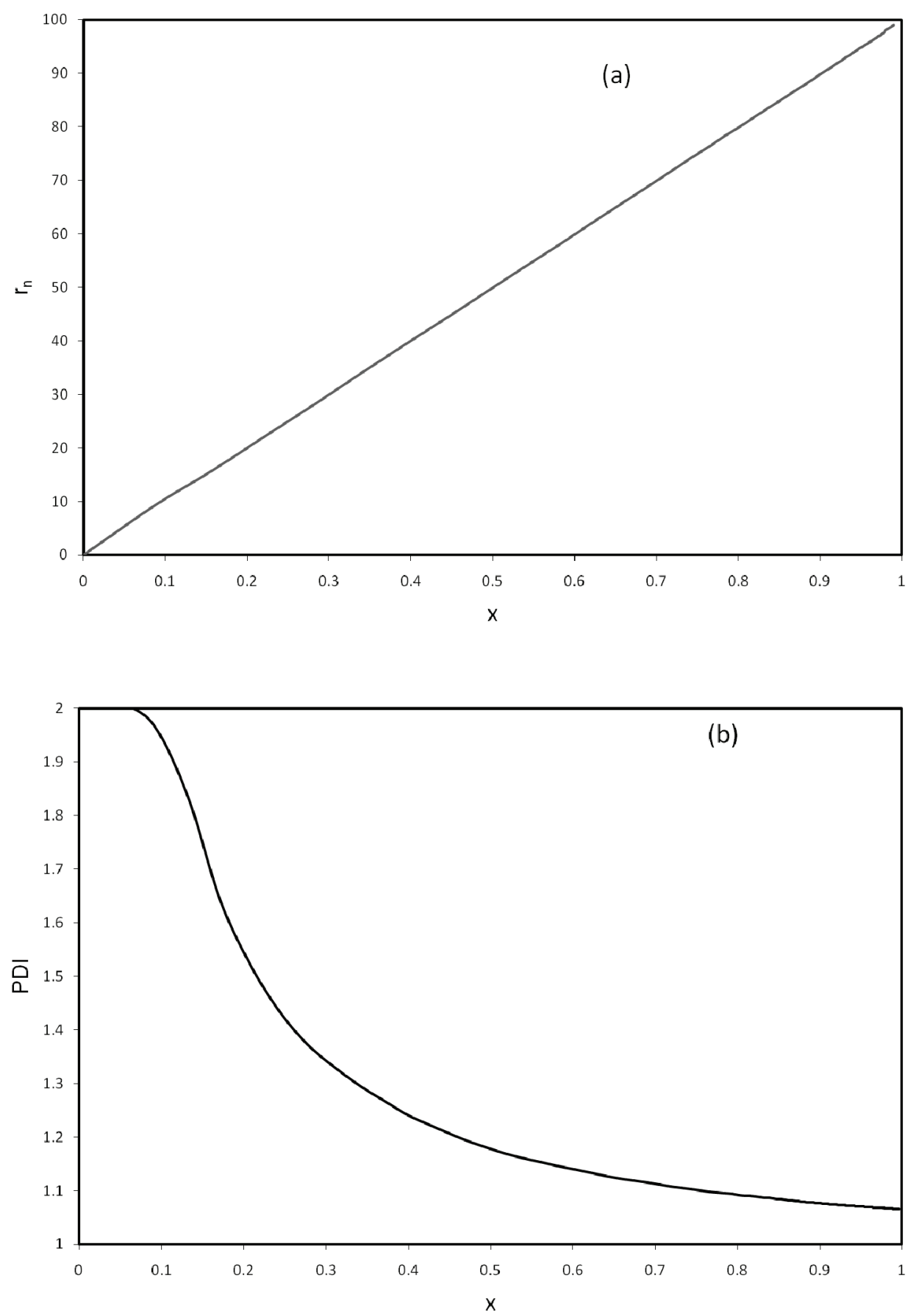


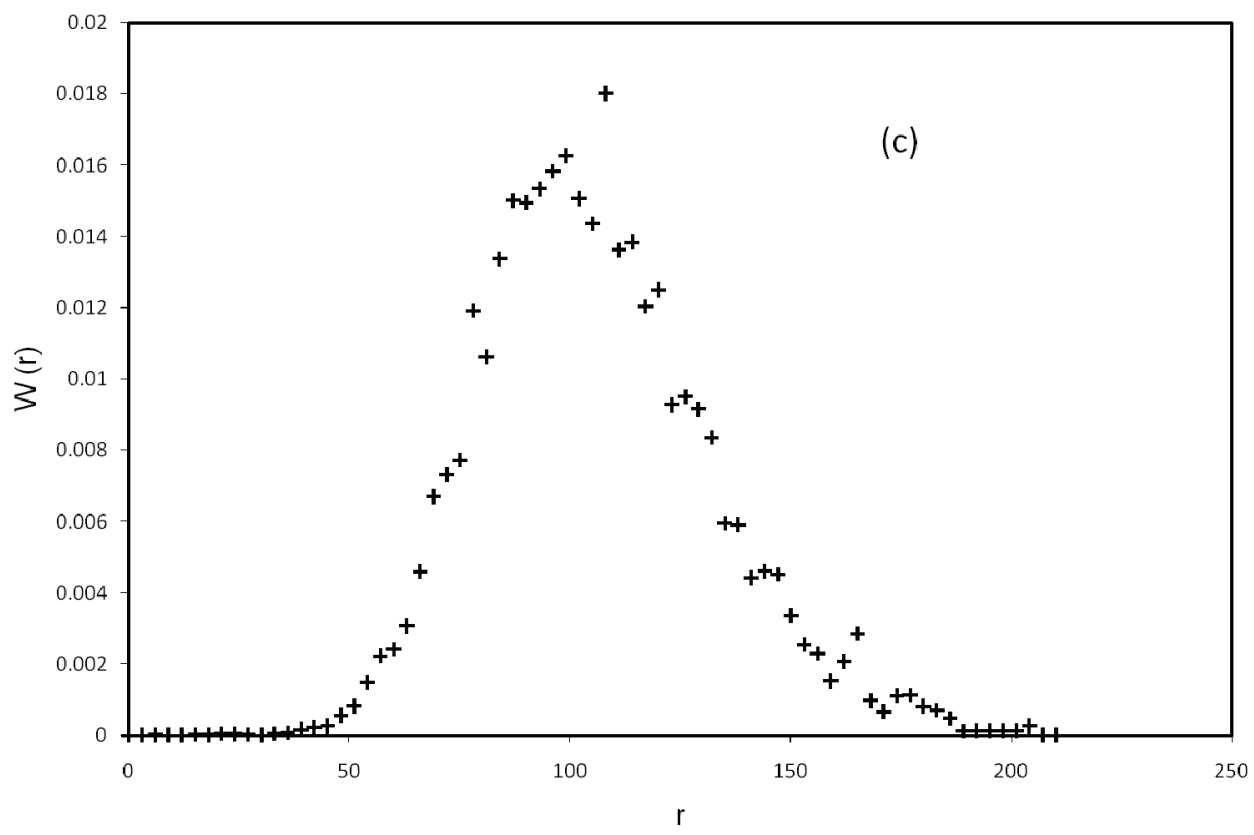

Fig. 2. Monte Carlo simulation results for the copolymerization of styrene and methyl methacrylate : (a) number average chain length $\left(r_{n}\right)$ as a function of conversion $(x)$, (b) PDI as a function of conversion, and (c) chain length distribution when conversion is $x=0.99$. The initial comonomer molar fractions in the reactor were $f_{0, S t}=0.5, f_{0, M M A}=0.5$.

Figure 3 shows the cumulative molar fraction of methyl methacrylate (MMA) in poly (acrylonitrile-co-methyl methacrylate) (AN-MMA) and poly(styrene-co-methyl methacrylate) (St-MMA). We can clearly see that in the St-MMA copolymer, the cumulative molar fraction of MMA remains almost constant throughout the polymerization. However, for the AN-MMA copolymer, the MMA molar fraction decreases from 0.5 to 0.3 .

Figure 4 shows the instantaneous molar fraction of MMA in AN-MMA and St-MMA copolymers. The instantaneous molar fraction of MMA in these copolymers differs significantly because of the difference in the reactivity ratios of the comonomer pairs. Because styrene and methyl methacrylate have very close reactivity ratios $(0.53$ and 0.46$)$ the molar fraction of MMA does not change significantly with conversion. On the other hand, the molar fraction of MMA in AN-MMA copolymers decreases with conversion because the reactivity ratios (0.14 and 1.3) of the two comonomers are very different. Figure 4 shows that no more MMA is incorporated in the chains after a total monomer conversion of approximately 0.8 . A similar trend is observed when the molar fraction of MMA is plotted as a function of the number average chain length. The comonomer composition drift in this case leads to the formation of a gradient copolymer with a terminal block composed of only acrylonitrile units. 


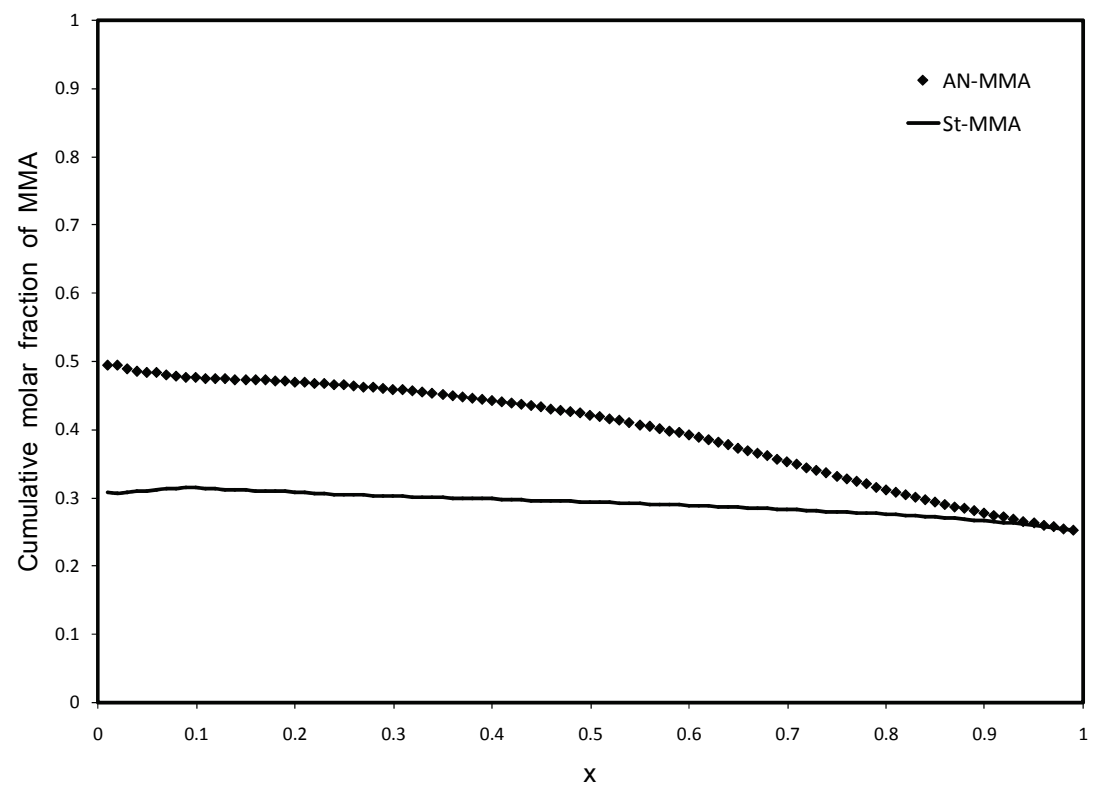

Fig. 3. Cumulative molar fraction of MMA in AN-MMA and St-MMA copolymers as a function of total comonomer conversion. The initial comonomer molar fractions in the reactor were $f_{0, M M A}=0.25$ and $f_{0, A N}=0.75$ or $f_{0, S t}=0.75$.

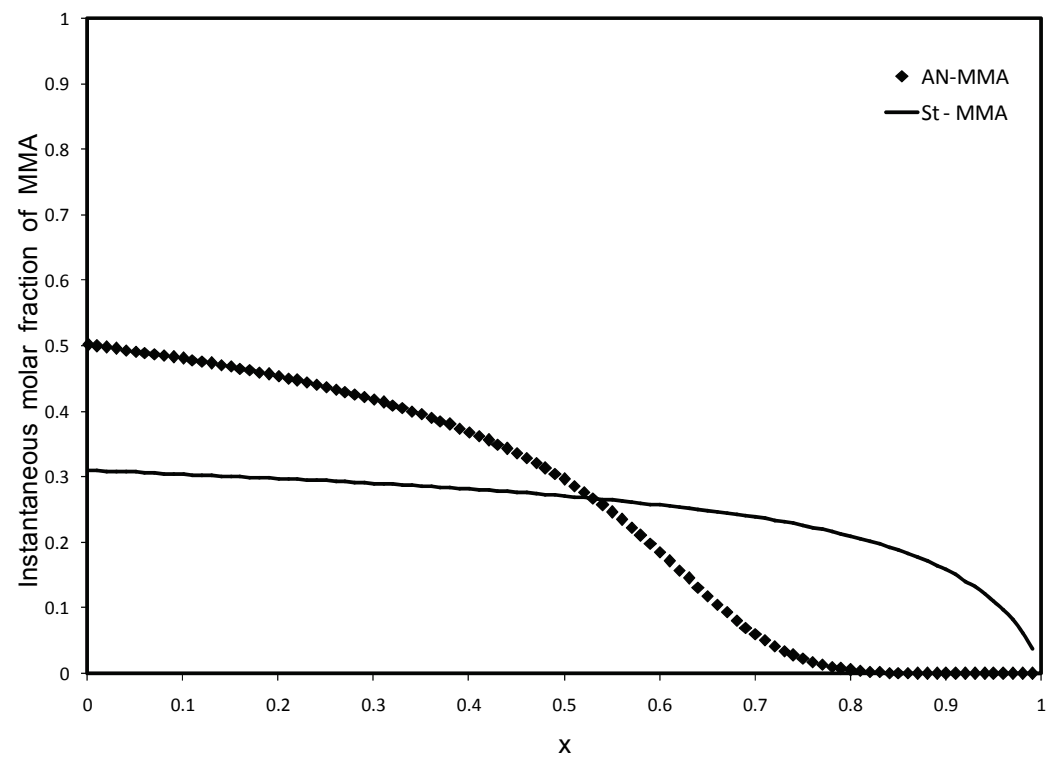

Fig. 4. Instantaneous molar fraction of MMA in AN-MMA and St-MMA copolymers as a function of total comonomer conversion. The initial monomer molar fractions in the reactor were $f_{0, M M A}=0.25$ and $f_{0, A N}=0.75$ or $f_{0, S t}=0.75$. 
In batch copolymerization using controlled/living polymerization, a gradient copolymer is only produced if comonomer composition drift is significant, i.e when the difference between the reactivity ratios of the comonomers is large and/or the initial comonomer concentrations are very different.

The DMC model also was used to describe the copolymerization of styrene and methylmethacrylate (St-MMA) or acrylonitrile and methylmethacrylate (AN-MMA) in a semibatch reactor. We compared the effect of using different initial comonomer concentrations and of slowly adding styrene, acrylonitrile or methyl methacrylate into the reactor as a side stream during the polymerization. We assumed that the autoclave reactor was isothermal and well-mixed.

Figure 5 compares the polydispersity index (PDI) of AN-MMA copolymers made in semibatch and batch reactors. Two different initial comonomer molar ratios (AN: MMA $=25: 75$ and 50:50) were simulated. For the semi-batch simulations, the acrylonitrile concentration was kept constant by slowly feeding the comonomer to the reactor as the polymerization proceeded. Both the batch and semi-batch reactors made copolymers with PDIs that followed the same trend: the PDI was initially high and then approached a value of approximately 1.1, as commonly observed in ATRP processes.

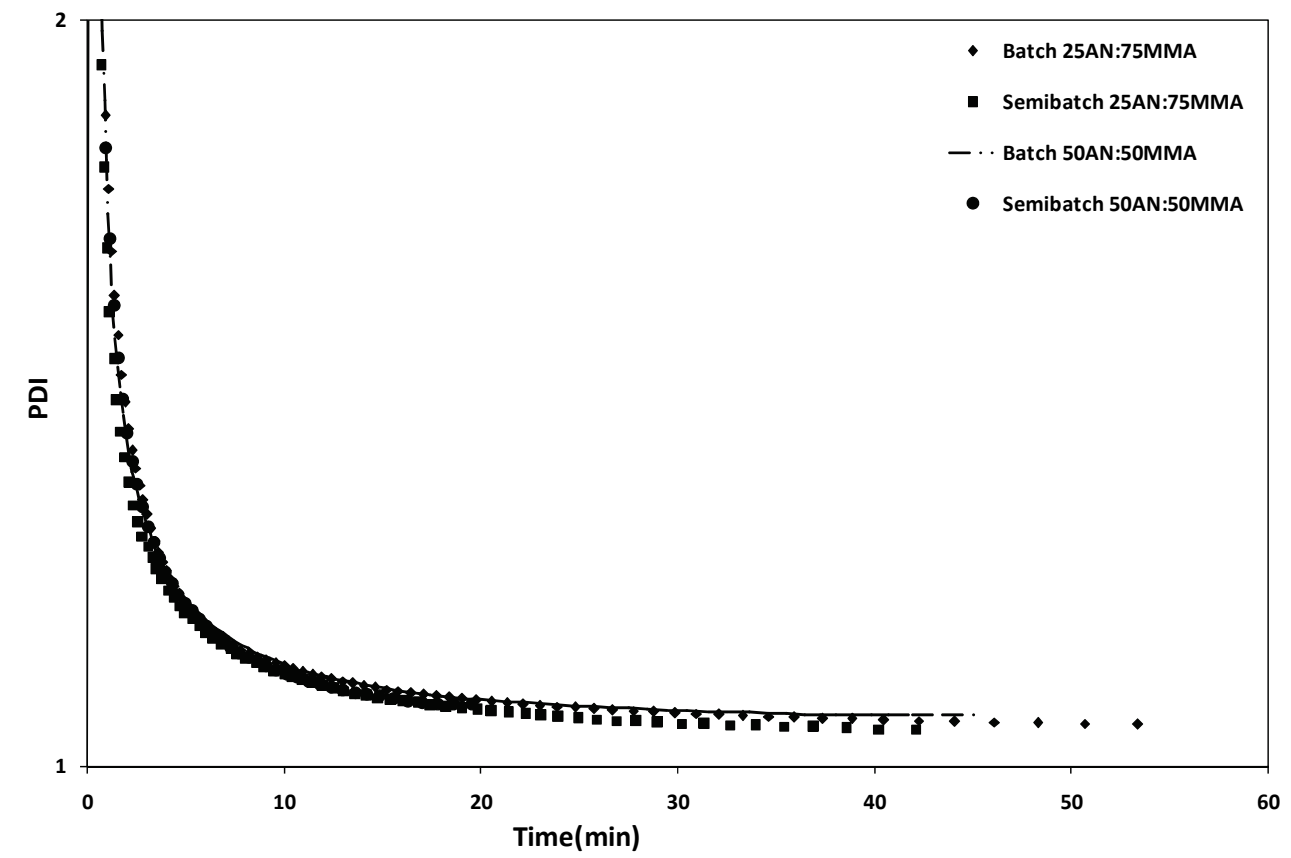

Fig. 5. PDI as a function of time for the copolymerization of AN and MMA in batch and semibatch reactors. The AN concentration was kept constant during the simulation of the semibatch reactor.

Figure 6 shows the instantaneous and cumulative molar fraction of AN in the copolymer as a function of polymerization time respectively. Figure 6.a shows gradient copolymers are 

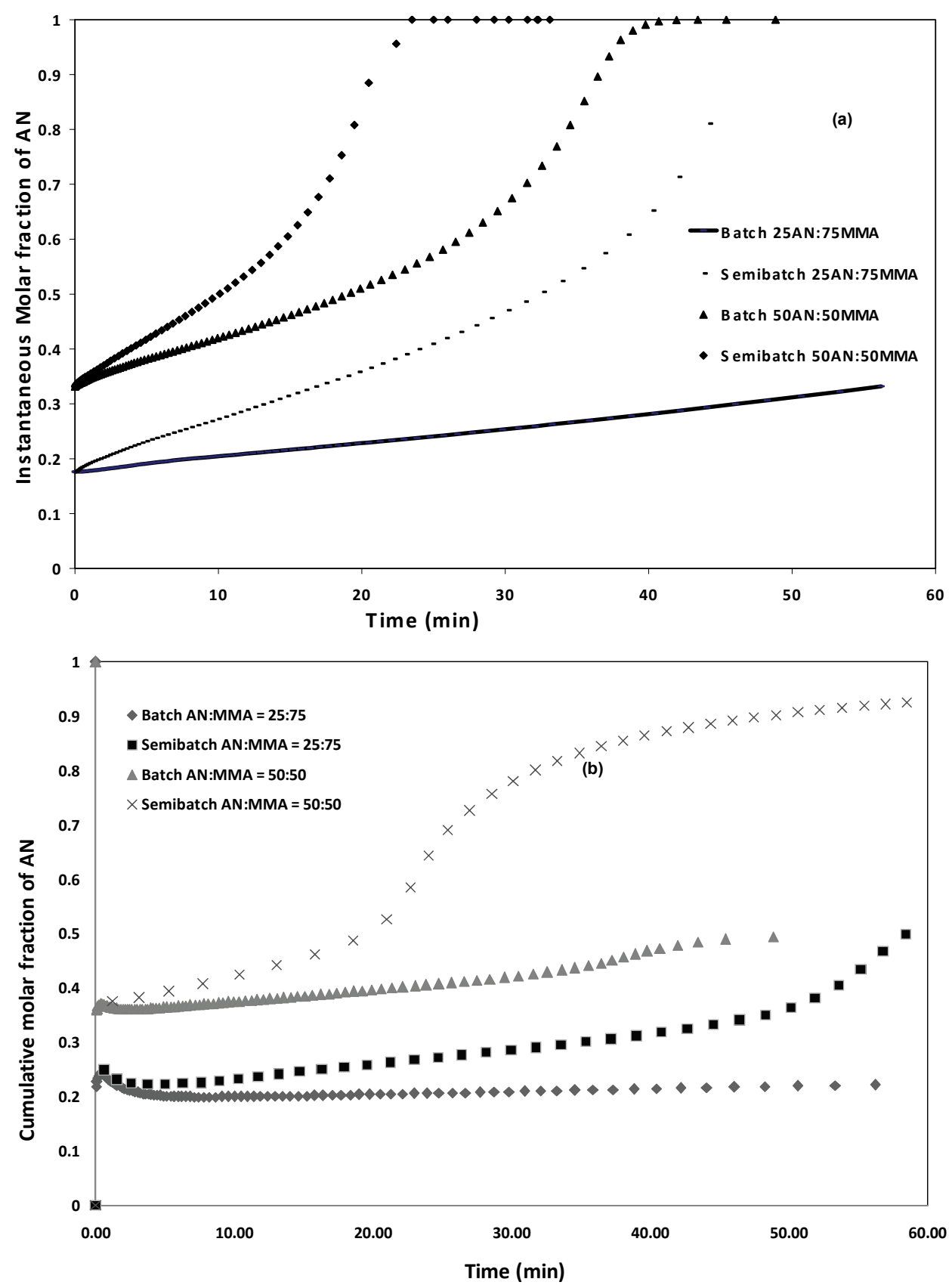

Fig. 6. (a) Instantaneous molar fraction of AN in AN-MMA copolymers as a function of polymerization time in batch and semibatch reactors. (b) Cumulative molar fraction of ANMMA copolymers as a function of polymerization time in batch and semibatch reactors. 
not made in the batch reactor when AN:MMA molar ratio is 25:75, but when AN:MMA is changed to 50:50, gradient copolymers will be produced for longer polymerization times. On the other hand, gradient copolymers are formed in the semi-batch reactor for both initial AN:MMA molar ratios at a shorter polymerization time.

Figure 6.b shows the cumulative molar fraction of acrylonitrile in the copolymer as a function of polymerization time. It clearly indicates the formation of gradient copolymers in a semi-batch reactor. Both initial molar concentrations show the formation of gradient copolymers. The AN:MMA molar ratio of 25:75 does not produce a gradient but when AN:MMA is changed to 50:50, gradient copolymers are formed. A longer AN block is formed while using a semi-batch than batch reactors as described in Figure 6. Thus, better gradient copolymers can be produced using semi-batch reactors.

Figures 7.a and 7.b compare the chain length distribution (CLD) of AN-MMA copolymers made in batch and semi-batch reactors for the two initial comonomer ratios. For an AN:MMA molar ratio of 25:75, the CLD of the copolymer made in the batch reactor is shifted to lower molecular weights. However, when AN:MMA is changed to 50:50, an opposite behavior is observed and the CLD of the copolymer made in the batch reactor is shifted to lower values. In the latter case, the semi-batch reactor can be used to produce a copolymer with higher molecular weight average without increasing the PDI. This is due to the higher propagation constant associated with AN. Hence, when AN content is increased, the rate of propagation is also increased thereby producing copolymer with higher molecular weight.

Figure 8 compares the CCDs of AN-MMA copolymers made in batch and semi-batch reactors. It is apparent that, the CCDs of copolymers made in the batch reactor are narrower than those made in the semi-batch reactor. In addition, the copolymers made in the semibatch reactor will always have a higher molar fraction or acrylonitrile, as expected.

The comonomer sequence distribution is characterized by its diads, triads, tetrads, and higher sequences, generally measured by NMR spectroscopy. Our DMC simulation program can also predict these sequences. Figures 9 to 14 show model predictions for diads and triads of styrene/MMA copolymers as a function of time when styrene is fed continuously to the reactor. Long polymerization times are needed to make gradient copolymers when MMA is fed to the reactor. Therefore, it is more convenient to produce gradient polymer when styrene is fed as the side stream. This could be attributed to the reactivity ratio of styrene which is slightly higher than MMA. Figures 9 to 14 clearly show that styrene diads and triads increase with increasing time for all initial monomer concentrations. The batch results of the present system did not show any formation of gradient polymers at all concentrations used while the semi-batch results predict the formation of gradient polymers for all the concentrations. Figures 9 to 14 were simulated at a maximum polymerization time of 100 minutes to better understand the formation of various diads and triads at a shorter timescale. As evident a clear increase in AN-AN blocks is found for all concentration except 25-75, but an increase in the timescale would result in the formation of gradient. The MMA-MMA blocks decreases for all concentration. Considering the homotriads, the AN-AN-AN blocks increases for all concentration within the timescale of 100 minutes. While a sharp decrease in the MMA-MMA-MMA triblocks are found for all concentration. Increase in the fraction of block copolymers are also found in our study. Clearly all the concentration form gradient polymers while a St:MMA molar ratio of 50:50 forms better gradient at the least polymerization time. Hence showing semibatch process could be very well utilized for making gradient polymers with styrene as the sidestream. 

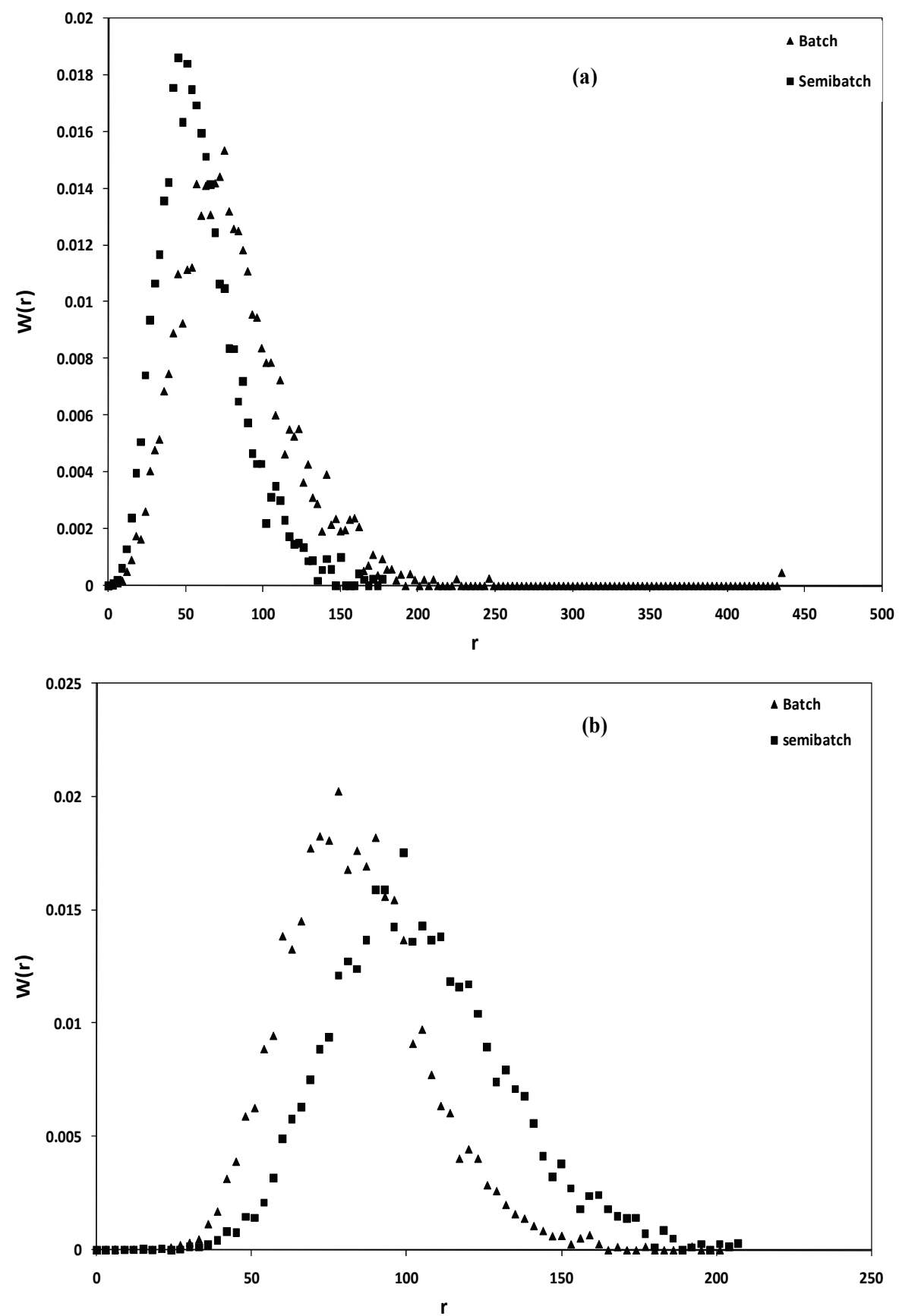

Fig. 7. Chain length distribution of AN-MMA copolymers made in batch and semibatch reactors. (a) AN:MMA $=25 / 75$ (b) AN:MMA $=50 / 50$. Polymerization time $=50 \mathrm{~min}$. 
Applying Dynamic Monte Carlo Simulation for Living Free Radical Polymerization Processes:

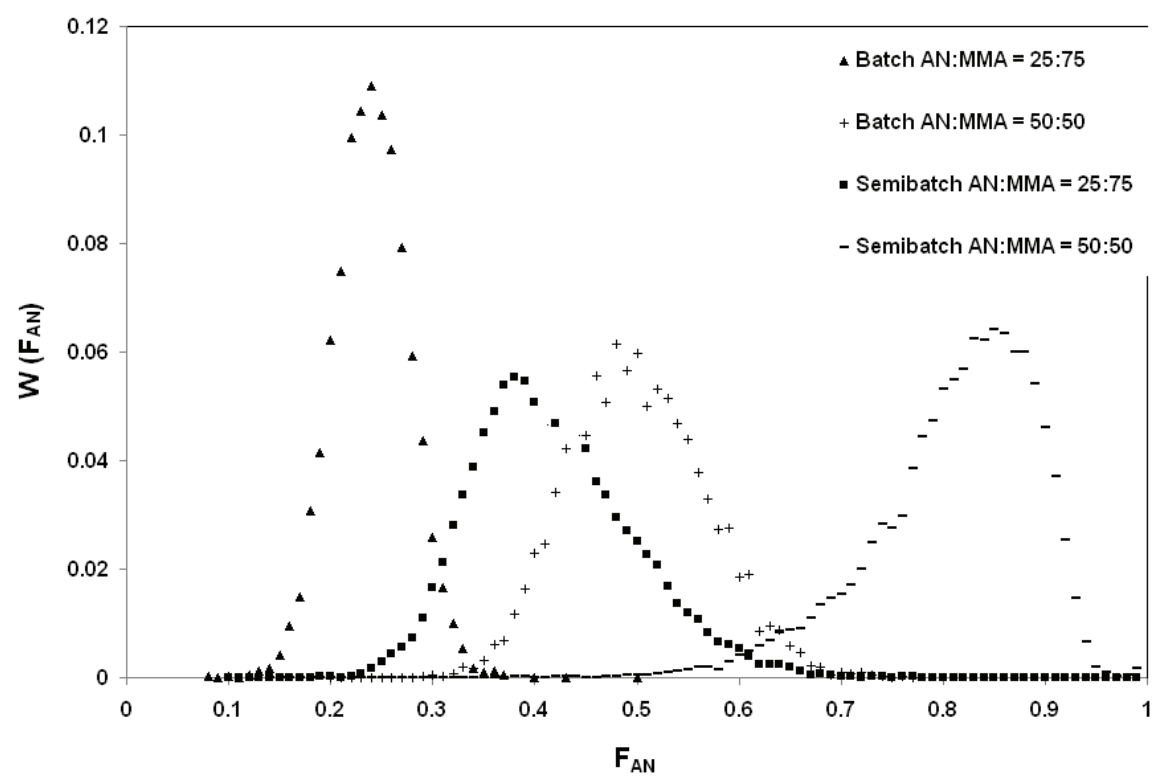

Fig. 8. Chemical composition distributions of AN-MMA copolymers made in batch and semibatch reactors. Polymerization time $=30 \mathrm{~min}$.

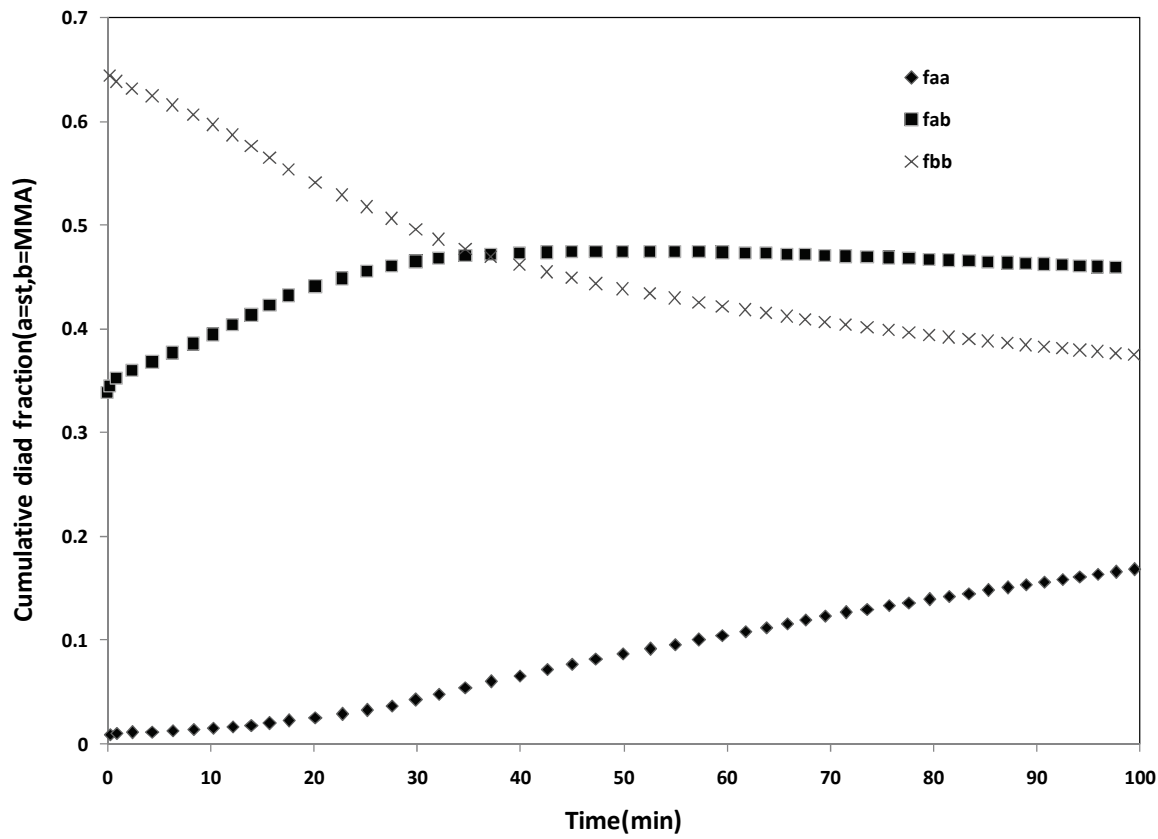

Fig. 9. Cumulative diad fraction as a function of total comonomer conversion for St-MMA system. The initial comonomer molar fractions are $f_{0, M M A}=0.90$ and $f_{0, S t}=0.10$. 


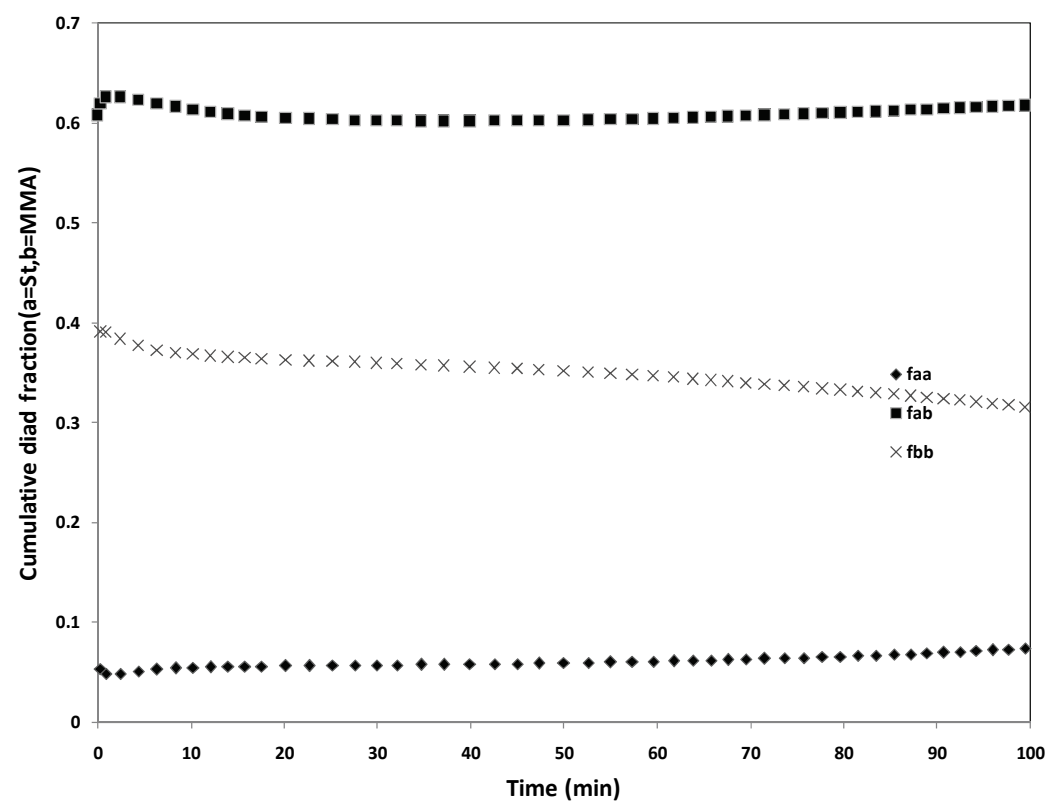

Fig. 10. Cumulative fraction of homodiads as a function of total comonomer conversion for St-MMA system. The initial comonomer molar fractions are $f_{0, M M A}=0.75$ and $f_{0, S t}=0.25$.

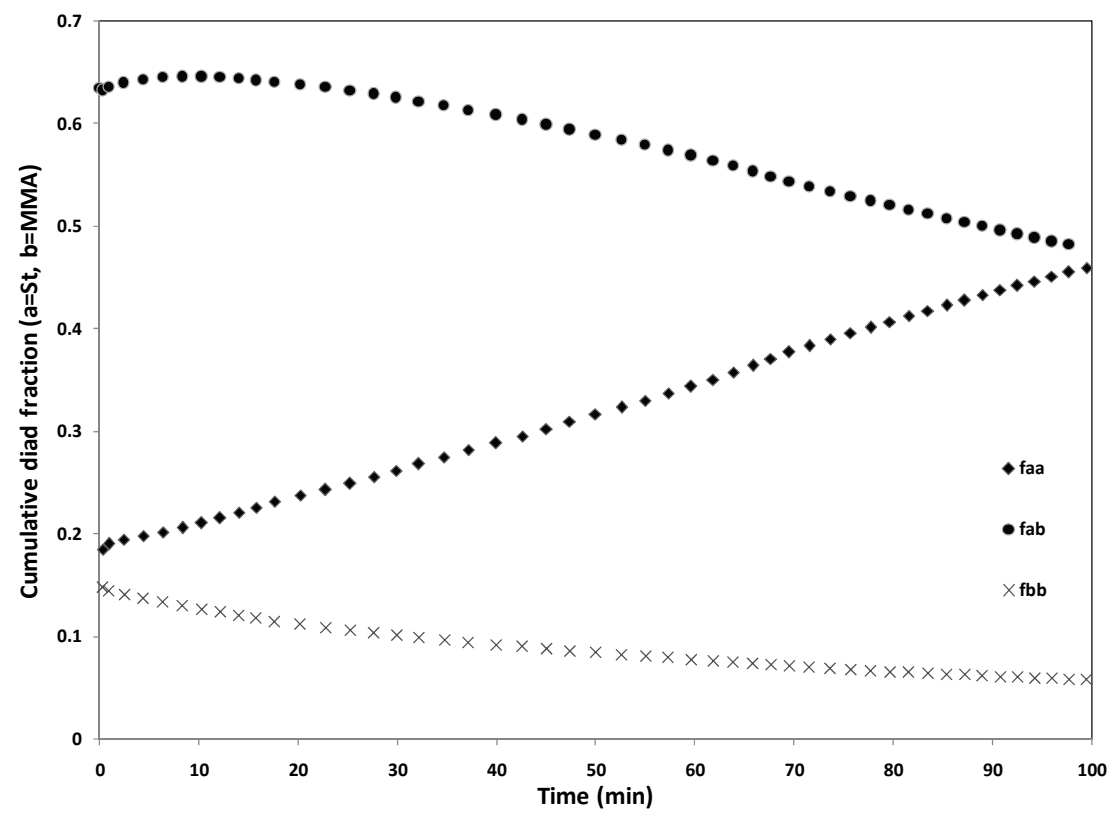

Fig. 11. Cumulative diad fraction as a function of total comonomer conversion for St-MMA system. The initial comonomer molar fractions are $f_{0, M M A}=0.50$ and $f_{0, S t}=0.50$. 
Applying Dynamic Monte Carlo Simulation for Living Free Radical Polymerization Processes:

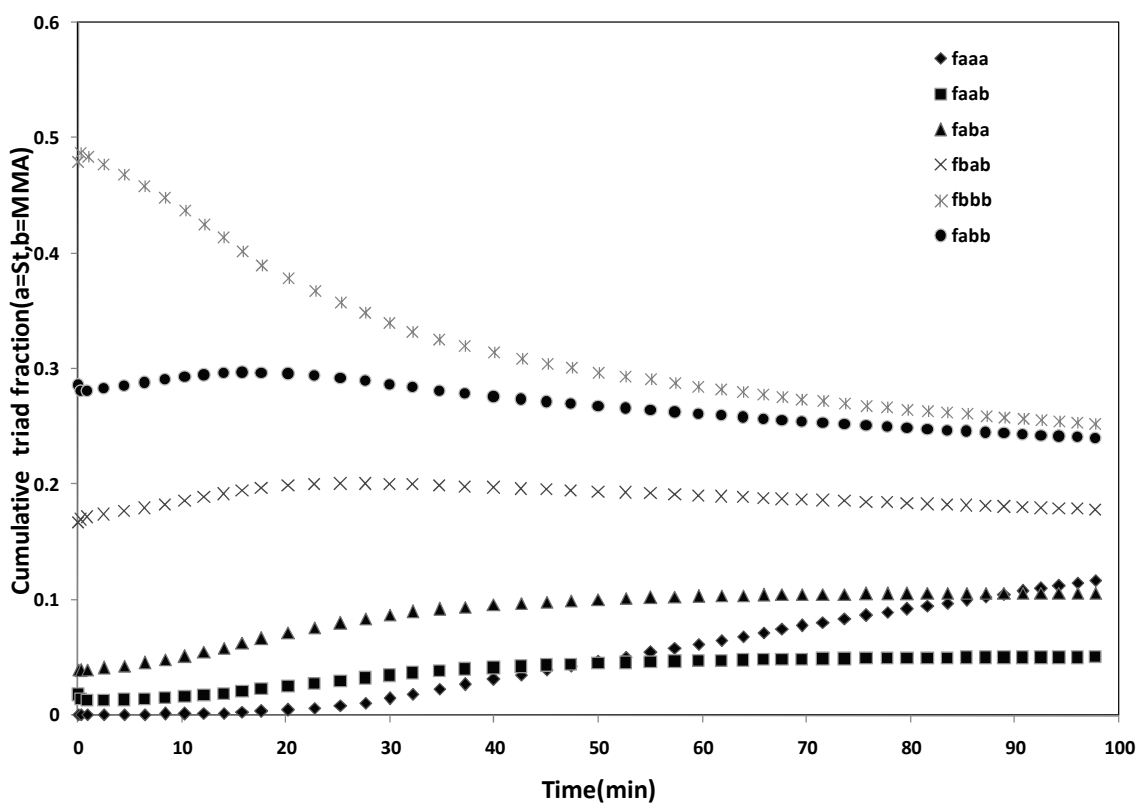

Fig. 12. Cumulative triad fraction as a function of total comonomer conversion for St-MMA system. The initial comonomer molar fractions are $f_{0, M M A}=0.90$ and $f_{0, S t}=0.10$.

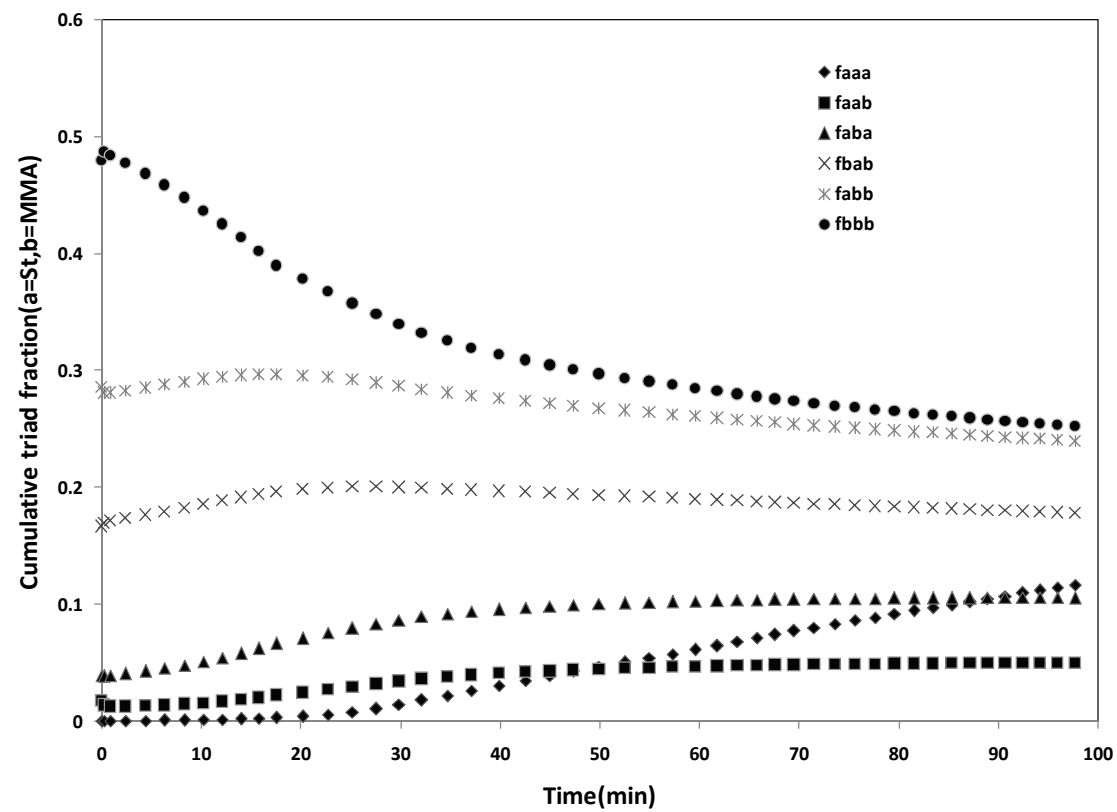

Fig. 13. Cumulative triad fraction as a function of total comonomer conversion for St-MMA system. The initial comonomer molar fractions are $f_{0, M M A}=0.75$ and $f_{0, S t}=0.25$. 


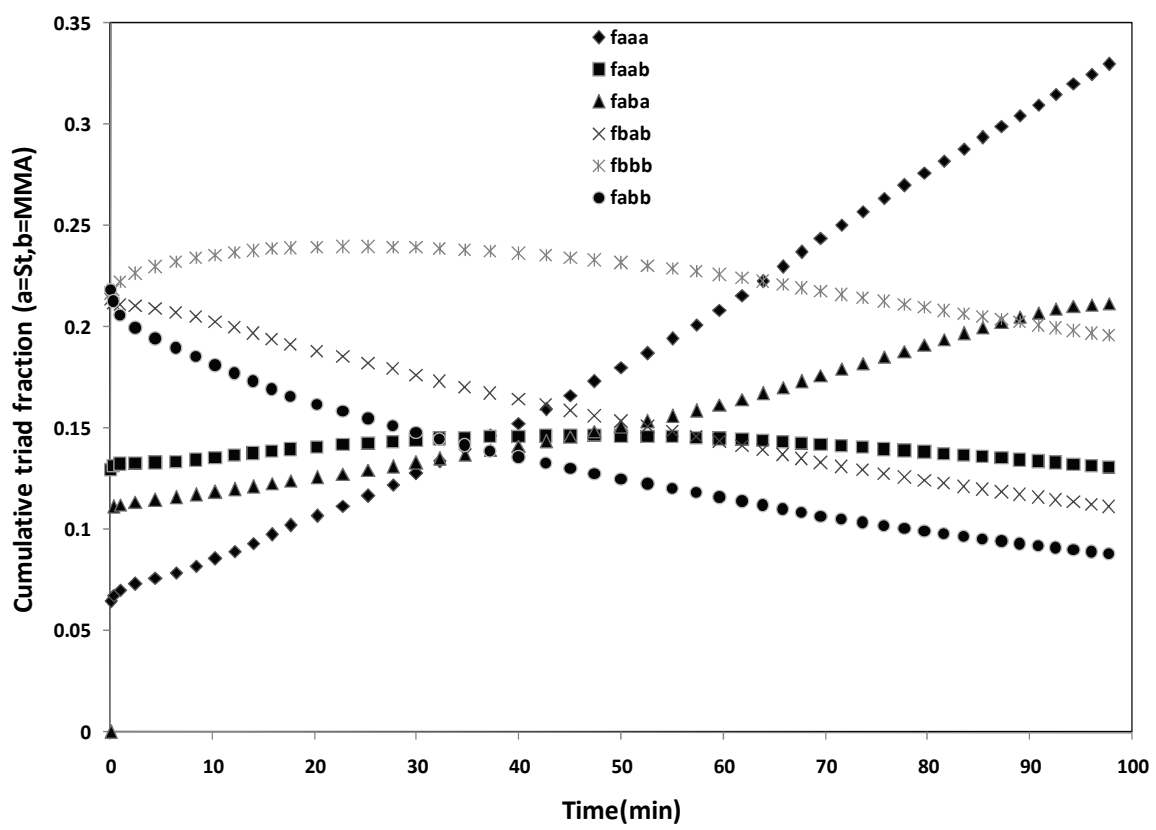

Fig. 14. Cumulative triad fraction as a function of total comonomer conversion for St-MMA system. The initial comonomer molar fractions are $f_{0, M M A}=0.50$ and $f_{0, S t}=0.50$.

\section{Conclusion}

DMC model was developed for the simulation of atom transfer radical copolymerization using Monte Carlo simulation. The model can predict average molecular weight, polydispersity index, MWD, CCD, SLD and copolymer composition as a function of polymerization time in semi-batch reactors. Two case studies (styrene-co-methyl methacrylate and acrylonitrile-co-methyl methacrylate) were chosen to demonstrate the effect of semi-batch method and monomer feed composition.

The simulations show that the instantaneous molar fraction of methyl methacrylate does not change significantly for poly(styrene-co-methyl methacrylate) copolymers made in a batch reactor starting with different comonomer molar ratios as methyl methacrylate and styrene have close reactivity ratios $(0.53$ and 0.46$)$ and, therefore, produce nearly random copolymer chains. On the other hand, the instantaneous molar fraction of methyl methacrylate in poly(acrylonitrile-co-methyl methacrylate) decreases with conversion and reaches zero around $80 \%$ of the total monomer conversion. There is a clear difference in the reactivity ratios ( 0.14 and 1.3) for this system. Composition drift, in this case, leads to the formation of gradient copolymer chains. The simulation for the varying monomer feed composition showed that the chance of forming gradient acrylonitrile-methyl methacrylate copolymers increases when the initial molar fraction of acrylonitrile is much higher than that of methyl methacrylate.

The simulation clearly showed the impact of using semi-batch for the formation of gradient copolymers. The system utilizing styrene as semi-batch showed that increasing the styrene 
content formed a gradient while increasing MMA content also formed gradient at the expense of high polymerization time but produced a narrow molecular distribution. The AN-MMA system followed the same trend. Gradient was formed in shorter polymerization time while employing AN as the sidestream. Even though batch process also produced gradient polymers, the semi-batch process utilized lesser polymerization time and lesser concentration of AN than its batch counterpart. The vital fact is the production of gradient polymers with great control enhancing the use of semi-batch technology. The model also showed its capability to produce tailor-made gradient polymers.

\section{References}

[1] Matyjaszewski K. Prog Polym Sci 2005; 30:858.

[2] Davis KA, Matyaszewski K. Adv Polym Sci 2002; 159:2.

[3] Matyjaszewski K, Xia J. Chem Rev 2001; 101:2921.

[4] Kamigaito M, Ando T, Sawamoto M. Chem Rev 2001; 101:3689.

[5] Benoit D, Chaplinski V, Braslau R, Hawker CJ. J Am Chem Soc 1999; 121: 3904.

[6] Rodlert M, Harth E, Rees I, Hawker CJ. J Polym Sci Polym Chem Ed 2000; 38:4749.

[7] Chiefari J, Chong YK, Ercole F, Krstina J, Jeffery J, Le TPT, Mayadunne RTA, Meijs GF, Moad CL, Moad G, Rizzardo E, Thang SH. Macromolecules 1998; 31: 5559.

[8] Moad G, Chiefari J, Chong YK, Krstina J, Mayadunne RTA, Postma A, Rizzardo E, Thang SH. Polym Int 2000;49: 993.

[9] Matyjaszewski K. J Macromol Sci Pure Appl Chem 1997; A34:1785.

[10] Matyjaszewski K, Xia J. Handbook of radical polymerization. New York: Wiley; 2002. p. 523.

[11] Matyjaszewski K, Ziegler MJ, Arehart SV, Gresztra D, Pakula T. J Phys Org Chem 2000; 13:775.

[12] Arehart, SV, Greszta D, Matyjaszewski K. Polym Prepr Am Chem Soc Div Polym Chem 1997; 38:705.

[13] Chen G, Wu Z, Wu J, Li Z, Li F. Macromolecules 2000;33:232.

[14] Uegaki H, Kotani Y, Kamigaito M, Sawamoto M. Macromolecules 1998; 31:6756.

[15] Al-Harthi M, Soares JBP, Simon LC. Macromol Theory Simul 2006; 15: 198.

[16] Zhu S. Macromol Theory Simul 1999; 8:29.

[17] Delgadillo-Velazquez O, Vivaldo-Lima E, Quintero-Ortega IA, Zhu S. AIChE J 2002;48:2597.

[18] Al-Harthi M, Soares JBP, Simon LC. Macromol Chem Phys 2006; 207:469.

[19] Al-Harthi M, Soares JBP, Simon LC. Macromol React Eng 2007; 1:468.

[20] Zhang M, Ray WH. J Appl Polym Sci 2002; 86:1630.

[21] Szablan Z, Toy AA, Terrenoire A, Davis TP, Stenzel MH, Muller AHE, Barner-Kowollik C. J Polym Sci Polym Chem 2006;44:3692.

[22] Shipp DA, Matyjaszewski K. Macromolecules 2000; 33:1553.

[23] Lutz J, Matyjaszewski K. Macromol Chem Phys 2002; 203:1385.

[24] Fu Y, Mirzaei A, Cunningham MF, Hutchinson RA. Macromol React Eng 2007;1:425.

[25] Tobita H. Macromol Theory Simul 2003; 12:32.

[26] Lu J, Zhang H, Yang Y. Makro Chemie Theory Simul 1993; 2:747.

[27] He J, Zhang H, Chen J, Yang Y. Macromolecules 1997; 30:8010.

[28] Al-Harthi M, Soares JBP, Simon LC. Macromol React Eng 2007; 1:95. 
[29] Al-Harthi M, Soares JBP, Simon LC. Macromol Symp Polym React Eng 2006; 243:83.

[30] Al-Harthi M, Soares JBP, Simon LC. Macromol Mat Eng 2006;291:993.

[31] Gillespie DT. J Phys Chem 1977; 81:2340.

[32] Keramopoulos, A. ; Kiparissides, C. ; Macromolecules 2002, 35, 4155.

[33] Buback, Gilbert, M.; Hutchinson, R.; Klumperman, R.; Kuchata, B.; Manders, F.; O’Driscoll, B.; Russell, K.; Schweer, G. J. Macromol. Chem. Phys. 1995, 196, 3267.

[34] Achilias, D. S.; Kiparissides, C. Macromolecules 1992, 25, 3739.

[35] Suzuki, H.; Mathot, V. B. Macromolecules 1989, 22, 1380.

[36] Hui, A. W. ; Hamielec, A. E. J. Appl. Polym. Sci. 1976, 16, 749.

[37] Keramopoulos, A. ; Kiparissides, C. Macromolecules 2002, 35, 4155.

[38] Yaraskavitch, I. M.; Brash, J. L.; Hamielec, A. E. Polymer 1987, 28, 489

[39] Matyjaszewski, K.; Ziegler, M. J.; Arehart, S. V. J. Phys. Org. Chem. 2000, 13, 775.

[40] Brandrub, J.; Immergut, E.; Grulke, E. Eds. Polymer Handbook, 4th ed.; Wiley: New York, 1999.

[41] Pittman-Bejger, T. P. Real-Time Control and Optimization of Batch Free-Radical Copolymerization Reactors. Ph.D. Thesis, University of Minnesota, 1982.

[42] Al-Harthi, M.; Abbasi, S. H.; Soares, J. B. P., Chemical Engineering Science, submitted.

[43] Al-Harthi, M.; Soares, J. B. P.; Simon, L. C. Macromol. React. Eng. 2007, 1, 468. 


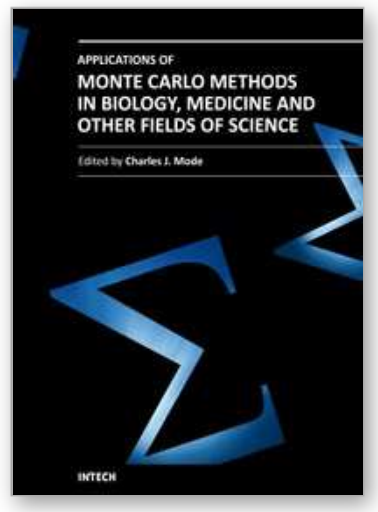

\section{Applications of Monte Carlo Methods in Biology, Medicine and Other Fields of Science}

Edited by Prof. Charles J. Mode

ISBN 978-953-307-427-6

Hard cover, 424 pages

Publisher InTech

Published online 28, February, 2011

Published in print edition February, 2011

This volume is an eclectic mix of applications of Monte Carlo methods in many fields of research should not be surprising, because of the ubiquitous use of these methods in many fields of human endeavor. In an attempt to focus attention on a manageable set of applications, the main thrust of this book is to emphasize applications of Monte Carlo simulation methods in biology and medicine.

\section{How to reference}

In order to correctly reference this scholarly work, feel free to copy and paste the following:

Mamdouh A. Al-Harthi (2011). Applying Dynamic Monte Carlo Simulation for Living Free Radical

Polymerization Processes: Emphasis on Atom Transfer Radical Polymerization (ATRP), Applications of Monte Carlo Methods in Biology, Medicine and Other Fields of Science, Prof. Charles J. Mode (Ed.), ISBN: 978-953307-427-6, InTech, Available from: http://www.intechopen.com/books/applications-of-monte-carlo-methods-inbiology-medicine-and-other-fields-of-science/applying-dynamic-monte-carlo-simulation-for-living-free-radicalpolymerization-processes-emphasis-on

\section{INTECH}

open science | open minds

\section{InTech Europe}

University Campus STeP Ri

Slavka Krautzeka 83/A

51000 Rijeka, Croatia

Phone: +385 (51) 770447

Fax: +385 (51) 686166

www.intechopen.com

\section{InTech China}

Unit 405, Office Block, Hotel Equatorial Shanghai

No.65, Yan An Road (West), Shanghai, 200040, China

中国上海市延安西路65号上海国际贵都大饭店办公楼 405 单元

Phone: +86-21-62489820

Fax: $+86-21-62489821$ 
(C) 2011 The Author(s). Licensee IntechOpen. This chapter is distributed under the terms of the Creative Commons Attribution-NonCommercialShareAlike-3.0 License, which permits use, distribution and reproduction for non-commercial purposes, provided the original is properly cited and derivative works building on this content are distributed under the same license. 